\title{
INTRACRANIAL ANEURYSM OF THE VERTEBRAL ARTERY*
}

H. GIDEON WELLS, M.D.

CHICAGO

Although small aneurysmal dilatations are common in any and all of the cerebral vessels, large intracranial aneurysms are rare. Thus, Hoffmann, ${ }^{1}$ in reporting on seventy-eight intracranial aneurysms observed during twenty years' examination of medicolegal cases in Vienna, describes chiefly minute dilatations or diffuse enlargement of the cerebral arteries, and not aneurysms of a size that would be likely to produce pressure symptoms. Most of these cases had come to necropsy because of sudden death from rupture of the dilatations, and had not been observed clinically. The aneurysms were distributed as follows in seventy-five cases:

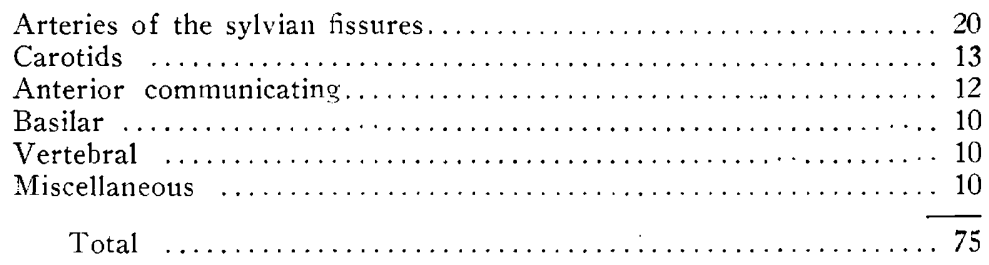

Of these, fifty-three were in women and twenty-two in men, which reverses the proportions usually abserved in aneurysms. It is to be noted that of the ten aneurysms of the vertebral artery, seven were on the left side; this predominance of the left side is usually described. Thus, Oppe, ${ }^{2}$ who in 1892 collected reports of seven cases of aneursyms of the vertebral artery, found that six were in the left.

Möser, ${ }^{3}$ describing three cases of what were virtually simple dilatations of the left vertebral artery, comments on the fact that thrombosis and embolism also usually affect the left vertebral artery. He made a study of the vertebral arteries in several bodies and found that the left artery is usually somewhat larger than the right (average, 2.43 as against $2.18 \mathrm{~mm}$. diameter), but that there is almost always a constriction at the point where the left vertebral joins the basilar, and less often on the right side, the average amount of narrowing being 0.318 and $0.24 \mathrm{~mm}$. for the left and right arteries, respectively.

* Presented by request before the Chicago Neurological Society, Dec. 15, 1921.

* From the Department of Pathology, University of Chicago, and the Otho S. A. Sprague Memorial Institute.

1. Wien. klin. Wchnschr. 7:824, 1894.

2. München. med. Abhand1. Ser. 2, 1892; quoted by Steckelmacher.

3. Möser: Deutsch. Arch. klin. Med. 35:418, 1884. 
In 142 cases of cerebral aneurysm reviewed by Krey ${ }^{4}$ none was in the vertebral arteries. Beadles ${ }^{5}$ compiled 555 cases of aneurysm of the cerebral arteries, all but 114 of which had been previously published. Unfortunately, he gives no analysis of this great material, but he has little to say concerning vertebral artery aneurysms, so presumably they were not numerous. He mentions only three such cases. The chief facts brought out by him are that in 46.3 per cent. of cerebral aneurysms the first symptom was apoplexy, in 67 per cent. death was preceded by apoplexy, and in 20.7 per cent. there were clinical evidences of intracranial tumor, which most often occurred with aneurysms of the basilar artery, which he discusses at some length. In only 16.39 per cent. was there no cerebral or meningeal hemorrhage. He describes one aneurysm of the left internal carotid artery which measured $13 / 4$ by $11 / 8(45 \mathrm{~cm}$. by $29 \mathrm{~cm}$.) inches, and states that this ranks among the largest intracranial aneurysms on record. "Its size has been exceeded by few, probably less than a dozen." These large aneurysms have arisen mostly from either the carotid or the basilar artery; he makes no mention of vertebral aneurysms in this group. Some of these aneurysms were the size of "a small orange," "a duck's egg," "a small hen's egg," "the size of a nut," whatever these comparisons may signify. Some, with measurements given, exceeded 2 inches in diameter. The largest vertebral aneurysm that I have found reported, that of Steckelmacher, is uncertain since the diagnosis rested on clinical evidence only. The aneurysm eroded the left half of the supra-occipital bone, and formed a large visible external swelling. The patient was still alive when the case was reported, so the origin cannot be considered as positively established.

The classical illustration of aneurysm of the vertebral artery published by Cruveilhier ${ }^{7}$ in his famous atlas, involved the right vertebral artery, and, to judge from the illustration, measured about $15 \mathrm{~mm}$. in diameter.

There has appeared recently a report of a case of vertebral aneurysm of comparatively large size, described by J. Floyd Morrow. ${ }^{8}$ This was observed in a body used for dissection in a medical school, and consequently there was no history.

The man was apparently 50 years of age, and, as no other evident cause for his death was found, it was assumed that he had died from paralysis of

4. Inaug. Dissert. Greiswald quoted by Rhein: J. Nerv. \& Ment. Dis. 41:360, 1914.

5. Beadles: Brain 30:285, 1907.

6. Steckelmacher: Deutsch. Ztschr. Nervenheilk. 54:347, 1916.

7. Cruveilhier: Anatomie Pathologique du Corps Humain 2:28, 1835, pl. 3.

8. Morrow, J. Floyd: Med. Rec. 100:894, 1921. 
the vital centers. The aneurysm is described as "a spontaneously cured fusiform aneurysm of the right vertebral artery. The aneurysmal dilatation began $1.5 \mathrm{~cm}$. from the bifurcation of the basilar artery, and increased abruptly to its greatest diameter of $2.5 \mathrm{~cm}$. This extreme dilatation was continued for a distance of $3 \mathrm{~cm}$. downward and the artery again very abruptly assumed its normal diameter." There was a channel on the side toward the medulla, of approximately normal size. There was much calcification of the wall. The left vertebral artery was crowded laterally and showed a dilatation for about $2.5 \mathrm{~cm}$. of its course with a diameter of nearly $1 \mathrm{~cm}$. This artery was very sclerotic as also was the circle of Willis. The medulla was pressed into an unrecognizable mass by the aneurysm. The anterior surface of the medulla was concave, much flattened and pushed backward between the cerebellar lobes, but there was no softening. The pons was pressed slightly upward on the left. Much degeneration of sensory and motor tracts was shown by Marchi staining. There is no statement made as to evidence of syphilis elsewhere in the body.

Most of the other cases recorded concern small aneurysms, like the "cherry pit" sized aneurysm of the left vertebral artery reported by Schultze, ${ }^{9}$ which was unusual in producing a marked convulsive tic involving the left facial nerve, without degeneration of the nerve. In this case death resulted from pulmonary tuberculosis. We also have the two vertebral aneurysms observed among twenty-two cases of ruptured intracranial aneurysms described by Wichern. ${ }^{10}$ Both of these were in males, one in the right vertebral artery, 3 to $4 \mathrm{~mm}$. in diameter, and one in the left, "a pea sized sac."

Weidman ${ }^{11}$ states that since Beadle's report in 1907 only seven cases have been indexed up to 1915 . The largest of these aneurysms was reported by Boinet, ${ }^{12}$ measuring 30 by $15 \mathrm{~mm}$., involving the left vertebral artery, and associated with several gummas of the brain and meninges. An aneurysm like that in Wiedman's case also occurred in a man, aged 40, with syphilis, but it was only "pea sized."

A striking feature about most of the ruptured cases, however, is the lack of any mention of the presence of evidences of syphilis. Usually the absence of such evidences is particularly mentioned.

Turnbull ${ }^{13}$ discusses the etiology of forty-eight cerebral aneurysms and finds that none of them seemed to be of syphilitic origin, although he recognizes that this is the dominant cause of aneurysm of the aorta, and occasionally in other arteries. In this series he attributed fifteen aneurysms to infected emboli and thirty-three to medial degeneration

9. Virchows Arch. f. path. Anat. 65:385, 1875.

10. Wichern: Deutsch. Ztschr. f. Nervenh. 44:220, 1912.

11. Weidman, Fred D.: Ruptured Aneurysm of the Right Vertebral Artery, J. A. M. A. 65:1105 (Sept. 25) 1915; Am. J. M. Sc. 151:427, 1916.

12. Compt. end. Soc. de Biol. 69:210, 1910.

13. Turnbull: Brain 41:50, 1918. 
following congenital developmental deficiency. Hedinger ${ }^{14}$ reports an aneurysm ( $1 \mathrm{~cm}$. by 4 to $5 \mathrm{~mm}$.) in the left vertebral artery observed shortly after a fall backward downstairs with injury to the neck and shoulders, and believes that the aneurysm was of traumatic origin since there were no evidences of arterial disease elsewhere, and no signs of syphilis. He speaks of having had also three cases of ruptured aneurysm of the "arteria vertebralis et basilaris" in syphilitic patients, without giving details.

Several other writers on intracranial aneurysm have attributed importance to traumatism in their etiology. It is indeed easy to imagine that the larger arteries may readily suffer traumatism from violent blows on the skull, since we know from the evidence concerning fractures and cerebral contusions a contre-coup, that suddcn alterations in intracranial relations take place that must almost certainly put a sudden severe strain on the large vesse's at the base on account of their fixation to the skull.

Direct traumatic aneurysms in the cervical portion of the vertebral artery have been described, especially from wounds received in the World War, but these do not concern us here. The literature has been largely collected by Kuttner ${ }^{15}$ and Kausch. ${ }^{16}$

The evident rarity of large intracranial aneurysms in the vertebral arteries makes it desirable to put on record a case that I have recently examined, despite the fact that no adequate neurologic examination was made before death. This is especially regrettable since the size and location of the aneurysm were such that symptoms of a cerebellopontile angle tumor should certainly have been present, and we know that some at least were.

\section{REPORT OF A CASE}

The subject was a colored man, 54 years old, who entered the Illinois Central Hospital on Dec. 21, 1920, complaining of pain in the left side, loss of weight and weakness. He had difficulty in urination; the urine was scanty, and the patient had had nocturia during the last three months, getting up two or three times during the night and passing only a small amount of urine. $\mathrm{He}$ had had some dizziness since September, during which month it was marked. He had also diminished vision.

The patient gave a history of typhoid, pneumonia and measles during child. hood, and malaria twenty-two years ago. He used whisky slightly and admitted having had gonorrhea but no chancre. His wife was living and well; she had not had children, but had an abortion soon after marriage. Two of his brothers were dead, and he had four sisters who were living and well. The man had been ill for about four months; he became ill in bed in September and had worked two weeks since that time.

14. Hedinger: Cor.-Bl. f. schweiz. Aerzte 47:1393, 1917.

15. Kuttner: Beitr. klin. Chir. 108:1, 1917.

16. Zentralbl. f. Chir. 45:885, 1918. 
Physical Examination (made in the hospital).-The pupils reacted to light and accommodation and were regular. The patient expectorated large quantities of whitish yellow sputum having a foul odor. The lungs showed dulness over both bases. Mucous râles were present over both sides anteriorly. Several teeth were missing and one was carious. The tongue was furred. The tonsils were hidden. No paralyses of any kind were noted.

The apex beat was under the nipple at the fourth interspace. The left border of the heart was $2 \mathrm{~cm}$. outside the nipple. The right side was under the sternum. The heart sounds were normal.

The abdomen was flat, contained no fluid, showed no tenderness and no organs were palpable. The genitals were normal. There was a slight inguinal adenopathy. The knee reflex was absent, the patient being moribund.

Roentgen-ray examination showed pyorrhea of all the remaining teeth. The heart was greatly enlarged, lying in a transverse position, greatly distended and pulsating heavily. The urine showed a few pus cells and hyalin casts. While in the hospital the patient coughed a great deal, especially when trying to swallow liquids, which he swallowed with much difficulty.

Course of Illness.-On January 1, the patient fell out of bed. On January 2, he was unable to take food and coughed a great deal; his breathing was labored; he still swallowed with difficulty. On January 4 he was semiconscious, the pulse and the general condition were poor.

The temperature fluctuated between 101 and $103 \mathrm{~F}$. until the last day when it rose from 99 to 106 . The pulse increased from 100 on the day of admission to 160 on the day of death, January 5 .

These findings merely indicated a bilateral pneumonia, probably hypostatic, and in the advanced stage of this terminal infection, with the patient moribund most of the time, no evidence of nerve lesions was detected. Evidently there were no marked facial or ocular paralyses, since doubtless these would have been observed. After the necropsy the widow was interviewed, and we obtained the following additional facts:

History Obtained from Widoru.-When the patient was about 18 years old, while walking on a railroad trestle, he was struck by a train. He was knocked to the ground about 12 or 15 feet $(365.76$ to $457.2 \mathrm{~cm}$.) below, and his forehead hit a rock. He remained unconscious for three or four days. The injury on his forehead was described as being about "the size of a fifty-cent piece." He was treated at home and no surgical procedures were employed. As far as could be ascertained, there was no immediate functional effect, but the patient had said that he had felt foolish for some time afterward. He was married when 23. No history was obtainable of his condition in the interval between injury and marriage. He was apparently well until eight or ten years ago when he began complaining of headaches. At times he would sit and hold his head in his hands because of the pain. He complained particularly of pain at the top of his head where it felt "as if the flesh was nailed to his head." These headaches became worse. He worked as an elevator man for the last five years before his death.

About three years ago, while sitting in a chair, the patient had what his wife called a "spell." He shook all over for about ten or fifteen minutes, after which he had a high fever and sweated profusely, and said his eyes felt as if they were crossed. A physician was called, who advised him to stay in bed. He remained in bed five days and at home twelve days. His body was tender all over; he could not stand to be rubbed with a liniment. A physician 
prescribed mercury for him. He went back to work but was very weak for one week. A few months later in the same year he had another similar attack. During the attack his mind was clear. He went to work the next morning but was weak. Two months later he had a third attack and went to work the next morning but was weak the day following.

The following autumn he complained of his teeth and was advised to have them extracted. About three months later two teeth were extracted. A few months afterward he came home sick, still complaining of his teeth. He was advised by the company physician to have more teeth extracted, which was done, but no relief was obtained. He felt as if he were cross-eyed. $\mathrm{He}$ was fitted with two pairs of eyeglasses but obtained no relief. $\mathrm{He}$ was always complaining of roaring in his ears. After having the teeth extracted he went to work. One day in November, 1920, while at work, he had what was called a paralytic stroke. He fell down in the elevator and had to be assisted to his feet. Information was not obtained as to whether he became unconscious or not. He recovered from this attack and came home alone, but later found he could not walk steadily. About three weeks later he complained that his legs felt like lead although he was able to move them slightly. He lost control of urination and stools, became unable to articulate and could not swallow. He grew steadily worse. His eyes were affected so that he could not recognize objects held before them. Apparently no facial paralysis existed. He was then taken to the hospital.

The records of the company physician contain no reference to any symptoms that could be referred to the intracranial tumor, and physicians who saw him daily at his work observed no evidence of any facial paralysis.

Necropsy Examination.-This examination was performed about eighteen hours after death.

External Appearance: The body was that of a well nourished and well developed colored man about 54 years old. There was no icterus. The superficial lymph glands were not noticeably enlarged. There was no edema of the ankles. The edges of the tibiae were smooth and there were no scars on the external genitals. There was about $1 \mathrm{~cm}$. of subcutaneous fat. A small fatty hernia of the round ligament of the liver was found in the midline, about $2 \mathrm{~cm}$. in diameter.

Pleural Cavities: The left pleural cavity was free from fluid and from adhesions except between the pericardium and the base of the left upper lobe. The thymus was replaced by fat.

The right pleural cavity contained a few adhesions along the anterior margin of the lower lobe. Elsewhere it was free from adhesions and contained no fluids.

Pericardial Cavity: This was normal.

Mouth and Pharynx: Many teeth were missing, and there was infection of the gums around those remaining. Otherwise there were no changes.

Larynx and Trachea: These showed no changes.

Heart, Aorta and Vessels: The heart was considerably enlarged, chiefly by hypertrophy of the left ventricle. The coronary vessels from the outside showed many calcified spots. The inner surface of the coronary arteries showed numerous yellow sclerotic patches. The valves were normal. There were extensive subendocardial hemorrhages in the left ventricle, chiefly in the upper portion. The myocardium was apparently normal except for a few small areas of fibrosis. The wall of the left ventricle was $15 \mathrm{~mm}$., of the right ventricle 


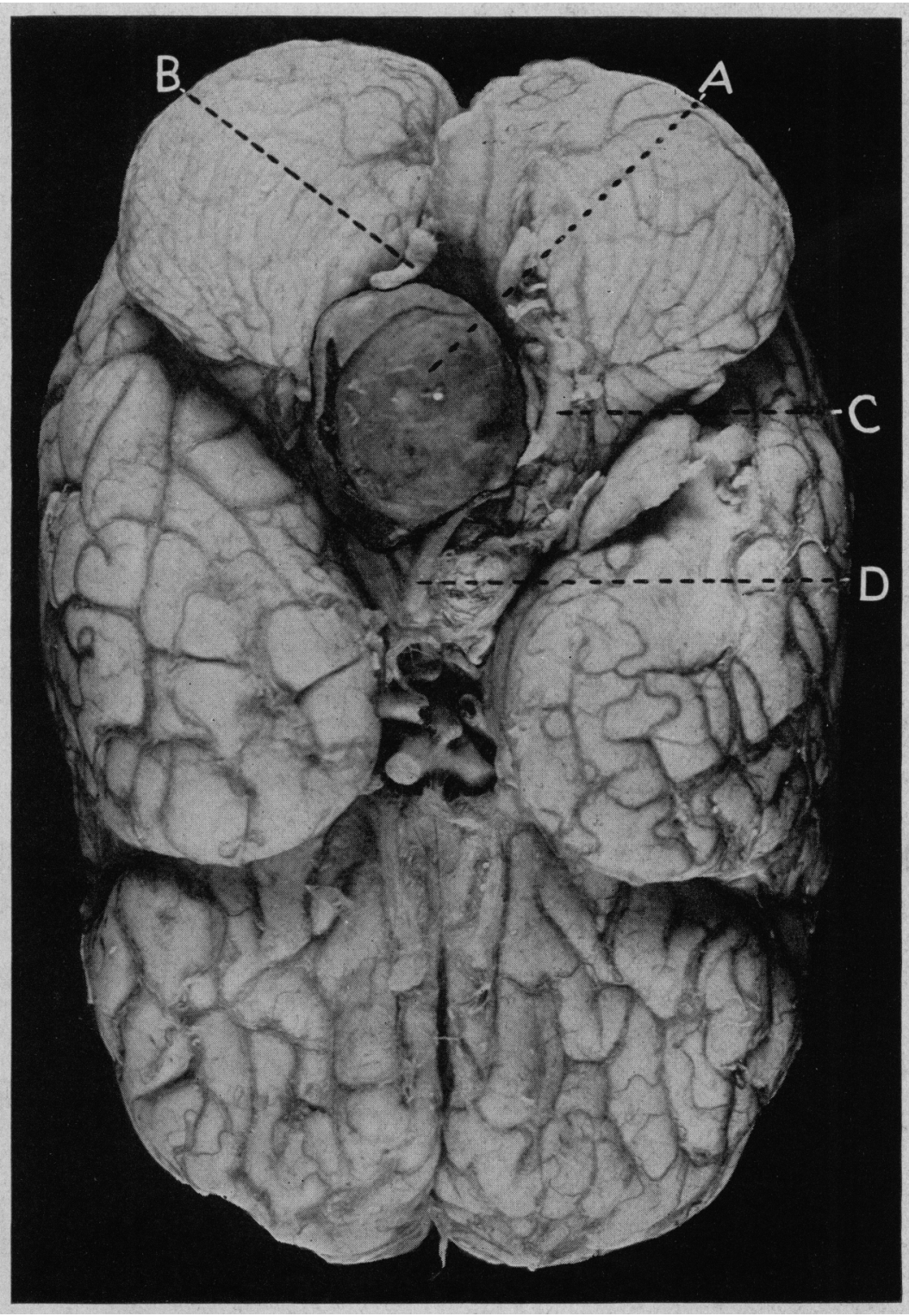

$A$, aneurysm of the left vertebral artery. Note that it has crowded and compressed the medulla upward and to the right. The defect observed was produced by removing material for sections. $B$. left vertebral artery which abruptly enters the ancurysmal sac; $C$, right vertebral artery; very sclerotic and crowded to the right; $D$, basilar artery. 
3 to $4 \mathrm{~mm}$., thick. There were a few small sclerotic patches in the arch and descending portion of the aorta. Both cavities of the heart were enlarged. The estimated weight of the organ was $400 \mathrm{gm}$.

Lungs: These showed marked bilateral hypostatic congestion with bronchopneumonia. The peribronchial lymph glands were extremely anthracotic but showed no evidences of caseation or calcification.

Liver and Gallbladder: These organs were normal.

Spleen: The spleen was small and distinctly fibrotic but not hard. There were fibrous adhesions between the spleen and the stomach.

Pancreas: The pancreas was small but normal in appearance.

Gastro-Intestinal Tract: The stomach showed numerous submucous hemorrhages, especially in the cardia, but was otherwise normal. The intestines showed no abnormality.

Suprarenals: The suprarenals were normal.

Kidneys: The kidneys were slightly smailer than usual. The cut surface of the left kidney showed the cortical markings well preserved. The capsule stripped readily leaving a smooth surface. The right kidney was also normal.

Urinary Tract: The urinary bladder was normal.

The prostate was somewhat enlarged. Nodules of hyperplasia were present in the median lobe, which protruded slightly under the mucosa of the bladder.

The seminal vesicles were normal.

There were numerous calcified thrombi in the periprostatic veins.

Lymph Glands: In general, these were normal.

Brain and Meninges: There was some rachitic deformity of the skull. The dura was very thin. The veins on the surface were distended. The vertex of the brain was in close contact with the dura. There was a small amount of clear cerebrospinal fluid. The sulci of the brain were much flattened, and the lateral ventricles were greatly dilated, each measuring $25 \mathrm{~mm}$. across in the widest parts. The hypophysis was normal. There was a nearly spherical, chocolate-brown tumor lying exactly at the junction of the pons and the medulla, both of which were compressed (see illustration). The tumor was nowhere adherent but was held in place by the blood vessels which entered it. About 80 per cent. of the tumor lay to the left of the median line. The basilar artery was crowded to the right and the left vertebral artery entered the tumor at a point near the inferior external angle. This artery reappeared again at a point $2 \mathrm{~cm}$. nearer the midline at the same level, at a point $7 \mathrm{~mm}$. from its junction with the basilar artery. The covering of the mass was continuous with that of the artery. The mass measured $34 \mathrm{~mm}$. in its anteroposterior diameter, $30 \mathrm{~mm}$. transversely, and $35 \mathrm{~mm}$. vertically. The superior surface forced itself into the space formed by crowding the medulla from the cerebellum, reaching a point about $15 \mathrm{~mm}$. above the inferior surface of the medulla. It was filled with a mass of dark, granular clot, somewhat laminated, with numerous calcified areas near the arterial side, and no fluid blood. The shape of the aneurysm had been partly molded by the adjacent brain tissue, for there was a somewhat pyramidal projection of the superior surface into the angle between the cerebellum, medulla and pons. The basilar and vertebral arteries were very sclerotic with areas of calcification, and the other cerebral arteries also were sclerotic.

The left vertebral artery had an extremely thick wall in the portion proximal to the aneurysm, with only a minute lumen remaining. Distal to the aneurysm it was occluded by a thrombus up to the point where it entered the basilar 
artery. The left vertebral artery was only about one half the size of the right, which was of the same diameter as the basilar artery. Apparently the left vertebral artery had been occluded for a long enough time to permit secondary sclerosis of the left and compensatory dilatation of the right vertebral artery. There were a few soft protrusions from the surface of the tumor which was covered by a smooth capsule. The cerebellum was slightly compressed at the anteromesial angle, and the medulla was pushed upward and to the right, being distinctly curved. The sixth to ninth left cranial nerves were flattened between the aneurysm and the cerebellum. The anterior margin of the tumor was just posterior to the fifth nerve origin.

There was a distinct grooving at the base of the skull involving the sphenoid bone and the occipital bone at the site where the tumor lay, just anterior to the foramen magnum. The dura was intact at this place; and the tumor was not adherent to it, nor was the dura abnormally adherent to the skull at this point. No evidence of any old injury to the skull was observed.

Microscopic examination of the wall of the aneurysm showed it to be composed solely of a thin membrane of dense hyalinized fibrous tissue, in which no elastic tissue or other remains of the artery wall could be detected, at least in the portion examined. The sac contained masses of clotted blood, much disintegrated, with no evidence of infection. There were a few small calcified masses attached to the vessel wall but within the clot. There was no evidence of organization of the clot, and no inflammatory reaction in the wall of the aneurysm.

The aorta showed merely a simple senile sclerosis. Neither here nor elsewhere could evidence of syphilis be found. No microscopic changes of importance were found in the other tissues.

Anatomic Diagnosis.-The anatomic diagnosis was: Saccular aneurysm of the left vertebral artery, with compression of the pons, cerebellum and medulla, and roots of the sixth to the ninth cranial nerves; pressure deformity of base of the skull; dilatation of the cerebral ventricles; bilateral hypostatic bronchopneumonia; diffuse senile arteriosclerosis; hypertrophy of the left cardiac ventricle; slight fibrous myocarditis; ventral fatty hernia; slight rachitic deformity of the skull and tibiae; subendocardial hemorrhages.

\section{SUM MARY}

A colored man, with no clinical or anatomic evidence of syphilis, but with a history of severe cranial traumatism many years before, died of hypostatic bronchopneumonia, without giving marked evidence of increased intracranial pressure or of cranial nerve paralysis during his last illness. Necropsy examination revealed a large aneurysm of the left vertebral artery, causing much deformity about the cerebellopontile angle, compressing the sixth to ninth cranial nerves, occluding the left vertebral artery, and, by pressure on the aqueduct of Sylvius, causing distinct internal hydrocephalus. That the swelling had been present for a long time was indicated by the presence of a distinct grooving in the floor of the skull beneath it. A necropsy inquiry revealed that the patient had had roaring in the ears, dizziness and "spells" three years before his death. Neuralgic pain and infection about the gums led 
to the extraction of several teeth four months before death. Two months later there was an attack of syncope. Three weeks before death difficulty of speech, decreased vision and difficulty in swallowing appeared, terminating in hypostatic bronchopneumonia.

As far as can be learned from the literature, this seems to be one of the largest vertebral aneurysms yet observed. It is unfortunate that the patient had not been the subject of a thorough neurologic examination during life, for the differentiation from a cerebellopontile angle tumor would have afforded difficulty. In two or three recorded cases a bruit has been heard over a vertebral aneurysm, but the clue would not have been present here since the artery was completely occluded. This aneurysm corresponds to the statement in the literature that intracranial aneurysms are not usually the result of syphilitic arteriosclerosis, but that they often give a history of antecedent cranial trauma. The presence of a distinct grooving of the skull beneath the aneurysm, without adhesion or erosion, would support the hypothesis that the aneurysm might have formed after the injury to the 18 -year-o!d boy. Probably this yielding of the skull permitted the aneurysm to reach the exceptionally large size it had attained. 